\title{
Relationship Between Incidence of Hyaline Membrane Disease and Maternal Hypertension During Pregnancy
}

\author{
Lasmida Nazir Nuriman, Dadang Sjarif Hidajat \\ (Department of Child Health, Medical School Padjadjaran University/ \\ Hasan Sadikin Hospital, Bandung)
}

\begin{abstract}
There have been controversies over the effect of hypertension in pregnancy on the incidence of type I neonatal respiratory distress syndrome or hyaline membrane disease (HMD). We investigated the relationship between the incidence of HMD and maternal hypertension during pregnancy in 91 infants at 34 weeks gestation or less. This retrospective cross sectional study included all live born babies between May 1, 1994 and Apri 30, 1995 at Dr. Hasan Sadikin General Hospital, Bandung. Maternal hypertension during pregnancy was diagnosed in 38 mothers of 91 infants studjed. The incidence of HMD $(5 \%)$ in the matemal hypertension during pregnancy group was significantly lower than the $62 \%$ in the normotensive group ( $<<0,01$ ). There was a negative correlation between the occurence of HMD and hypertension during pregnancy. We conclude that the risk of developing HMD in infants born to hypertensive mothers is significantly lower than those born to normotensive mothers. [Paediatr In. dones $1998 ; 38: 47-53]$
\end{abstract}

\section{Introduction}

Hyaline membrane disease (HMD) or respiratory distress syndrome (RDS) type I is a major cause of death in the newborn period. HMD occurs after the onset of breathing primarily in premature infants with insufficiency of the pulmonary surfactant; its incidence is inversely related to gestational age. Some matemal conditions such as hypertension during pregnancy and certain conditions of intrauterine stress may cause a rise of total glucocorticoid level and increase of surfactant synthesis.

The effect of hypertension in pregnancy on the incidence of HMD remains controversial. A number of studies have supported the widely accepted view that maternal

Author's address: Lasmida N Nuriman, MD, Department of Child Health, Medical School, Padjadjaran University, Jl. Pasteur 38, Bandung, Indonesia. Tel, 62-22-234426. Fax. 234913, 232216. 
hypertensive disease protects the development of HMD. Some workers have found that maternal hypertension associated with an decrease incidence of HMD, while others reported no such a change. These controversies led us to investigate the association between maternal hypertension and the incidence of HMD in infants less than 34 weeks gestation born in a referral hospital.

\section{Methods}

This study was undertaken at the Perinatology Ward, Department of Child Health of Hasan Sadikin Hospital, Bandung. A retrospective analysis was made on the incidence of HMD in babies with 34 weeks gestational age or less at this hospital from May 1, 1994 to April 30, 1995. The total number of infants identified was 101; eight of them were excluded because of incomplete diagnosis, and two because of maternal chronic hypertension, leaving 91 infants available for study. Thirty-eight (42\%) were bom to mothers with hypertension during pregnancy and the remaining $53(58 \%)$ were borm to normotensive mothers.

Information on perinatal factors was obtained from the review of mothers' and infants' medical records. Hypertension was defined as systolic and diastolic blood pressure of $>140 / 90 \mathrm{mmHg}$ on two occasions of more than six hours apart. Hypertensive disease was defined as acute if the onset of hypertension occurred after 20 weeks gestation and there was a complete resolution by 12 weeks postpartum.

Infant information include the respiratory status especially the presence or absence of respiratory distress. The diagnosis of HMD was established by using clinical (Silverman score), and radiographic criteria. Determination of gestational age was based on simplified Dubowitz and Ballard scores. Statistical analyses were performed by using chi-square test, t-test, and multiple logistic regression model with HMD as dependent variable and perinatal characteristics as independent variables.

\section{Results}

Neonatal factors associated with hypertension during pregnancy are shown in Table 1. There was no significant difference between both groups with respect to maternal age, sex, and mode of delivery. The body weight and length of infants born to hypertensive mothers was higher than that of non-hypertensive ones. We found that hypertension during pregnancy occurred most frequently in the first pregnancy (66\%); followed by second $(12 \%)$, and third pregnancy $(10 \%)$. Hypertensive mothers delivered more nonasphyxiated infants $(67 \%)(p<0.001)$. Compared with the normotensive mothers, those with hypertension delivered less infants with $\mathrm{RDS}(5 \%$ vs $63 \%, \mathrm{p}<0.001)$. 
Table 1. Association between perinatal characteristics and hypertension during pregnancy

\begin{tabular}{|c|c|c|c|c|}
\hline & Characteristics & $\begin{array}{l}\text { Hypertensive } \\
\quad(n=38)\end{array}$ & $\begin{array}{c}\text { Normotensive } \\
\quad(n=53)\end{array}$ & $p$ \\
\hline 1. & Mothers' age (yr.), mean (SD) & $25.2(5.9)$ & $26.8(5.9)$ & $p=0.208$ \\
\hline 2. & Gestational age (wk.), mean (SD) & $32.84(1.55)$ & $31.16(2.44)$ & $p<0.001$ \\
\hline 3. & Body weight (grams), mean (SD) & $2096(367)$ & $1439(587)$ & $p<0.001$ \\
\hline 4. & Body length $(\mathrm{cm})$, mean (SD) & $43.6(3.1)$ & $39.5(5.1)$ & $p<0.001$ \\
\hline \multirow[t]{3}{*}{5.} & Mode of delivery & & & \\
\hline & - Pervaginam & 35 & 43 & $p=0.241$ \\
\hline & - Caesarean section & 3 & 10 & \\
\hline 6. & First child, $n(\%)$ & $25(66 \%)$ & $16(30 \%)$ & $p=0.002$ \\
\hline \multirow[t]{3}{*}{7.} & Sex & & & \\
\hline & - Male & 20 & 30 & $p=0.871$ \\
\hline & = Female & 18 & 23 & \\
\hline
\end{tabular}

8. Asphyxia

- None
- Mild
- Moderate
- Severe
- Unknown
26

9

$10 \quad p<0.001$

6

212

1

24

1

9. Type IRDS (HMD)

$$
\begin{aligned}
& \text { - Yes } \\
& \text { - No }
\end{aligned}
$$

22

$33 p<0.001$

36

20

10. Intrauterine growth

\begin{tabular}{lrrr} 
- SGA & 2 & 14 & $p<0.001$ \\
- AGA & 36 & 39 & \\
\hline
\end{tabular}

Note: $n=$ number of subjects, $S D=$ standard deviation; $R D S=$ respiratory distress syndrome; $\mathrm{HMD}=$ hyaline membrane disease $; \mathrm{SGA}=$ small for gestational age; $\mathrm{AGA}=$ appropriate for gestational age 
Table 2. Association between perinatal characteristics and occurrence of HMD

\begin{tabular}{lccccc}
\hline \multicolumn{1}{c}{ Characteristic } & $\mathrm{HMD}(\mathrm{n}=35)$ & Non-HMD $(\mathrm{n}=56)$ & Total & $\%$ & $\mathrm{p}$ value \\
\hline Sex & & & & & \\
- Male & 22 & 28 & 50 & 54.9 & $\mathrm{p}=0.326$ \\
- Female & 13 & 41 & 45.1 & \\
Intrauterine growth & & & & & \\
- SGA & 6 & 10 & 16 & 17.6 & $\mathrm{p}=1.0$ \\
- AGA & 29 & 46 & 75 & 82.4 &
\end{tabular}

Gestational age (wk)

* $<28$

- $28-30$

- $31-32$

- 33-34

Birth weight (grams)

. $<1000$

- 1000-1499

- 1500-1999

- 2000-2499

- >2500

- Mean (SD)

Infant's length $(\mathrm{cm})$

- Mean (SD)

Mode of delivery

- Normal

- Cecarean section

Asphyxia

- None

- Mild

- Moderate

- Severe

- Unknown

$\begin{array}{rrrrr}5 & 1 & 6 & 6.6 & p=0.001 \\ 11 & 7 & 18 & 19.8 & \\ 10 & 11 & 21 & 23.1 & \\ 9 & 37 & 46 & 50.5 & \end{array}$


From the intrauterine growth point of view, we found that most infants of hypertensive mothers were appropriate for gestational age 36 cases $(94.7 \%)$ while those without hypertension the proportion of SGA was 39 out of 53. The difference of both gropus was statistiacally significant ( $\mathrm{p}<0.001)$.

Perinatal factors associated with HMD are shown in Table 2. It shows that male sex, intrauterine growth and mode of delivery were not associated with the incidence of HMD, On the other hand, infants who developed respiratory distress syndrome had significantly lower birth weight, body length and gestational age. Asphyxia, as reflected by low Apgar scores, occurred significantly more often in RDS than in control infants $(54.3 \%$ vs $5.7 \%)$.

The relationship between maternal hypertension and HMD is shown in Table 3. A significantly lower incidence of HMD was found in infants born to mothers with hypertension during pregnancy compared with those bom to normotensive mothers.

Table 3. Association between maternal hypertension and the incidence of HMD

\begin{tabular}{lccc}
\hline $\begin{array}{c}\text { Maternal } \\
\text { hypertension }\end{array}$ & $\begin{array}{c}\text { HMD } \\
(n=35)\end{array}$ & $\begin{array}{c}\text { Non-HMD } \\
(n=58)\end{array}$ & Total (\%) \\
\hline Yes & 2 & 36 & $38(42)$ \\
No & 33 & 20 & $53(58)$ \\
\hline \multicolumn{4}{c}{$x^{2}=28.021 ; p<0.001$}
\end{tabular}

Table 4. Logistic regression analysis between various variables and the incidence of HMD

\begin{tabular}{lrrrc}
\hline \multicolumn{1}{c}{ Variables } & Coef B & SE (B) & \multicolumn{1}{c}{$\mathrm{p}$} & Odds ratio \\
\hline Hypertension & -3.11 & 1.01 & 0.0019 & 0.04 \\
Infant's body weight & 0.27 & 0.46 & 0.55 & 1.31 \\
Infant's sex & -0.23 & 0.69 & 0.74 & 1.31 \\
Intrauterine growth & 1.35 & 0.89 & 0.13 & 3.87 \\
Gestational age & -0.58 & 0.46 & 0.21 & 0.56 \\
Asphyxia & 0.86 & 0.34 & 0.0019 & 2.36 \\
Mode of delivery & 0.47 & 0.58 & 0.42 & 1.61 \\
Coefficient A & -2.79 & 2.37 & 0.24 & \\
\hline
\end{tabular}

Note: Coefficient B is the regression coefficient of logistic regression, SE (B) is the standard error of coefficient of regression 
Multivariate analysis using multiple logistic regression model was performed to investigate further the association between the confounding effects of birth weight, intrauterine growth, gestational age, presence of asphyxia and mode of delivery (Table 4). After this adjustment, asphyxia and maternal hypertension were still a significant association to the occurrence of HMD.

\section{Discussion}

In 1973, Gluck and Kulovich demonstrated that matemal hypertension was associated with an accelerated maturation of the lecithin / sphyngomyeline ratio. ${ }^{1}$ This study was followed by supportive clinical studies which showed that respiratory distress was less frequent in premature infants following maternal hypertensive disease in pregnancy. ${ }^{2-5}$

Our study included only infants born with the gestational age of 34 weeks or less because the more mature infants were at a relatively low risk for significant morbidity or mortality from RDS. Physiologically the production of surfactant will increase rapidly after 34 weeks of gestational age.

This study demonstrated that infants of hypertensive mothers had a lower incidence of HMD compared with the infants of normotensive mothers (5\% vs $63 \%$ ). The mechanism responsible for the lower incidence of HMD in infants of hypertensive mothers is not clear. Several investigations suggest that fetal or maternal glucocorticoids may accelerate fetal lung maturation. We were unable to find any study on glucocorticoid levels in premature infants born to hypertensive mothers.

To sum up, we have shown that HMD was significantly lower in babies of hypertensive mothers both on bivariate and after adjusting for confounding variables by regression model. Further studies are therefore needed, preferably involving larger number of subjects to clarify the association of hypertensive mothers and the occurrence of RDS in their babies.

\section{References}

1. Gluck L, Kulovich MV. Lecithin/sphingomyelin ratios in amniotic fluid in normal and abnormal pregnancy. Am J Obstet Gynecol 1973;115: 539-46,

2. Chiswick ML, Burnard E. Respiratory distress syndrome. Lancet 1973;1:1060.

3. Pardi G, Marini A. Fetal lung maturation in toxaemia and estrogen therapy in management of respiratory distress syndrome. Lancet 1974;2:1453.

4. Chiswick ML. Prolonged rupture of membranes, preeclamptic toxaemia in respiratory distress syndrome. Arch Dis Child 1976; 51:674-79.

5. Yoon JJ, Schuyber K, Harper RG. The relationship between maternal hypertensive 
disease of pregnancy and the incidence of idiopathic respiratory distress syndrome. Pediatrics 1980; 65:735-9.

6. Lee KS, Eidelman AI, Tseng PI, Kandall SR, Gartner LM. Respiratory distress syndrome of the newborn and complications of pregnancy. Pediatrics 1976; 58:675-80.

7. Brazy JE, Grimm JK, Little VA. Neonatal manifestations of severe maternal hypertension occuring before the thirtysixth week of pregnancy. J Pediatr 1982; 100:265-71.

8. White E, Shy KK, Benedetti TJ. Chronic fetal stress and the risk of infant respiratory distress syndrome. Obstet Gynecol 1986; 67:57-62.

9. Hansen T, Corbet A. Lung development and function. In: Schaffer and Avery's Diseases in the newborm; 6th ed. Philadelphia: Saunders, 1991, 461-9. 